Published in "Acta Biomaterialia 10(7): 2996-3006, 2014"

which should be cited to refer to this work.

\title{
Plasma-functionalized electrospun matrix for biograft development and cardiac function stabilization
}

\author{
A.G. Guex ${ }^{\mathrm{a}, \mathrm{b}, \mathrm{c}}$, A. Frobert ${ }^{\mathrm{d}}$, J. Valentin ${ }^{\mathrm{d}}$, G. Fortunato ${ }^{\mathrm{a}}$, D. Hegemann ${ }^{\mathrm{a}}$, S. Cook ${ }^{\mathrm{d}}$, \\ T.P. Carrel ${ }^{\text {b }}$, H.T. Tevaearai ${ }^{\text {b }}$, M.N. Giraud ${ }^{\mathrm{d}, *}$ \\ a Empa, Swiss Federal Laboratories for Materials Science and Technology, 9000 St. Gallen, Switzerland \\ ${ }^{\mathrm{b}}$ Department of Cardiovascular Surgery, University Hospital and University of Bern, 3010 Bern, Switzerland \\ 'Graduate School for Cellular and Biomedical Sciences, University of Bern, 3010 Bern, Switzerland \\ ${ }^{\mathrm{d}}$ Cardiology, Department of Medicine, University of Fribourg, 1700 Fribourg, Switzerland
}

\begin{abstract}
Cardiac tissue engineering approaches can deliver large numbers of cells to the damaged myocardium and have thus increasingly been considered as a possible curative treatment to counteract the high prevalence of progressive heart failure after myocardial infarction (MI). Optimal scaffold architecture and mechanical and chemical properties, as well as immune- and bio-compatibility, need to be addressed. We demonstrated that radio-frequency plasma surface functionalized electrospun poly ( $\varepsilon$-caprolactone) (PCL) fibres provide a suitable matrix for bone-marrow-derived mesenchymal stem cell (MSC) cardiac implantation. Using a rat model of chronic MI, we showed that MSC-seeded plasma-coated PCL grafts stabilized cardiac function and attenuated dilatation. Significant relative decreases of $13 \%$ of the ejection fraction (EF) and 15\% of the fractional shortening (FS) were observed in sham treated animals; respective decreases of $20 \%$ and $25 \%$ were measured 4 weeks after acellular patch implantation, whereas a steadied function was observed 4 weeks after MSC-patch implantation (relative decreases of $6 \%$ for both EF and FS).
\end{abstract}

\section{Introduction}

Despite significant improvements in medical and surgical interventions, cardiovascular diseases remain the major cause of death in industrialized countries. Consequently, the urgent need for alternative therapies has been addressed, including strategies focusing on the possible reverse remodelling of the cardiac structure and recovery of the contractile function [1]. During the past decade, myocardial stem cell injection has provided encouraging clinical outcomes and might become an accepted therapy [2]. However, the ischemic myocardium represents a hostile environment and successful clinical implementation of cell therapy is thus hampered by several challenges, including poor survival of injected cells and their limited retention and engraftment [3-5].

The use of biomaterials to engineer exogenous micro-tissues for cell delivery may be an attractive strategy to promote reproducible prolonged cell survival and retention [6,7]. Polymeric matrices aim

* Corresponding author. Address: Cardiology, Department of Medicine, University of Fribourg, Ch. Du Musée 5, CH-1700 Fribourg, Switzerland. Tel.: +41 (0) 26 3008531.

E-mail address: marie-noelle.giraud@unifr.ch (M.N. Giraud). at providing a favorable environment for ex vivo cell adhesion and growth, and for facilitated implantation onto the ischemic myocardium $[4,8-13]$.

However, the pertinence of acellular patches for cardiac function improvement has been demonstrated [14,15]. Epicardial implantation of acellular patches after myocardial injury resulted in left ventricular (LV) function improvement and limited progression of LV dilation. Therefore, the relevance of cells implanted together with a scaffold remains an open question. The systematic comparison of therapeutic efficacy of the scaffold alone or with cells is of paramount importance to provide specific answers for any new patch.

Nevertheless, the choice of material, the consequential role of cell-matrix interactions and the vascularization of the biograft are major aspects to consider. Recent studies have highlighted the suitability of synthetic electrospun-based scaffolds that can be fine-tuned, with respect to their biocompatibility and their architectural, mechanical and chemical properties, in order to provide an optimal microenvironment for cell growth [16,17]. Electrospun fibres have been successfully used for the engineering of soft tissues [18] or cardiac valves [19]. Their application in myocardial tissue engineering is, however, still in its infancy. In vitro 
evaluations underpinned the suitability of electrospun membranes for cardiomyocyte guidance and differentiation as well as maintenance of their contractile function [20-22]. The fibrous, anisotropic architecture of electrospun scaffolds compared to solid substrates proved superior for cardiomyocyte maturation and, in particular, cell infiltration and multi-layered tissue formation [23-25].

Poly( $\varepsilon$-caprolactone) (PCL), a material approved by the US Food and Drug Administration, holds great potential for successful implementation due to its good immune-tolerance, high availability and practicable processability by electrospinning [26,27]. Previous studies highlighted the versatility of electrospun PCL to create synchronously beating multi-layered cardiac constructs [28,29]. However, in vivo evaluations of the efficiency of cell-seeded electrospunbased matrices applied onto infarcted myocardium are still lacking.

Due to the strongly hydrophobic nature of electrospun PCL matrices, an enhanced biological interface, holding particular importance in cell-matrix interactions, must be generated by surface functionalization. Several methods, among them blending of synthetic polymers with ECM proteins, are known to induce enhanced cell adhesion [30,31]. With respect to clinical application, naturally occurring proteins raise concerns due to their xenogenic origin, potential contamination and low availability at high costs [32]. To this end, the substitution of proteins or peptides by functional groups generated in wet-chemical or plasma-based processes presents a versatile advantage. Adapted process parameters during plasma polymerization allow for tissue specific functionalities and the formation of stable surface coatings [16,33,34].

In the current study, we aimed at developing a new plasmacoated, parallel-oriented electrospun PCL substrate that structurally and chemically provides adhesion sites for cellular attachment, is immune-tolerant and guarantees scaling up possibilities for translational research. The designed cardiac patch, acellular vs. seeded with mesenchymal stem cells (MSCs), was evaluated in a rodent model of chronic myocardial infarction (MI). We provide evidence that the designed matrices provide a safe and efficient substrate for MSC growth and delivery thereof to the ischemic heart. We furthermore report that this treatment induces improved performance of infarcted hearts with attenuation of LV dilatation and stabilized cardiac function.

\section{Materials and methods}

\subsection{Substrate production and characterization}

Fibrous substrates were produced and characterized as previously established in our group [16]. In short, a 15\% w/v PCL (Sigma-Aldrich, Buchs, Switzerland) spinning solution was prepared by dissolving PCL in a mixture of chloroform/methanol (9:1) (Sigma-Aldrich, Buchs, Switzerland). Solutions were processed by electrospinning at a flow rate of $30 \mu \mathrm{min}^{-1}$, with an applied field strength of $1 \mathrm{kV} \mathrm{cm}^{-1}$, and collected on a rotating $\operatorname{drum}(\sim 1000 \mathrm{rpm})$.

Electrospun patches were functionalized using a radio-frequency (RF) plasma process. An oxygen functional hydrocarbon layer $(\mathrm{a}-\mathrm{C}: \mathrm{H}: \mathrm{O})$ was deposited according to previously established protocols [35]. Briefly, 4 standard cubic centimetre per minute $(\mathrm{sccm})$ ethene $\left(\mathrm{C}_{2} \mathrm{H}_{4}\right), 24 \mathrm{sccm}$ carbon dioxide $\left(\mathrm{CO}_{2}\right)$ and $50 \mathrm{sccm}$ argon ( $\mathrm{Ar})$ were introduced into a symmetric reactor chamber. All gases were of 99.9 vol.\% purity and provided by Carbagas, Gümligen, Switzerland. RF power input was set to $34 \mathrm{~W}$ at a chamber pressure of $0.1 \mathrm{mbar}$ and plasma exposure time of $15 \mathrm{~min}$. Surface functionalization was characterized by X-ray photoelectron spectroscopy (XPS) analysis as previously reported [16].

Wettability was assessed by static contact angle measurements (Krüss GmbH, Hamburg, Germany). A drop of $10 \mu$ l distilled water was deposited on the fibrous substrates. Measurements were repeated three times.

Substrate morphology and fibre diameter (based on 100 individual measurements, Image J, free download under http://rsbweb.nih.gov/ij/) were characterized by scanning electron microscopy (SEM). Prior to imaging, substrates were gold-sputtered (Polaron Equipment, SEM coating Unit E5100, Kontron AG, Switzerland; $5 \mathrm{~mA}, 1 \mathrm{mbar}, 7 \mathrm{~min}$ ) and recorded on a Hitachi S4800 (Hitachi High-Technologies, US, Illinois, USA) at an accelerating voltage of $2 \mathrm{kV}$ and $10 \mu \mathrm{A}$ current flow.

Elasticity ( $E$ modulus) of the patches and yield strength were assessed by stress-strain measurements on an MTS 858 Mini Bionix (Bionix systems, MTS Eden Prairie, USA) equipped with a $25 \mathrm{~N}$ load cell and a displacement rate of $0.15 \mathrm{~mm} \mathrm{~s}^{-1}$. Substrates were pre-incubated in culture medium or seeded with MSCs, respectively, prior to measurements.

\subsection{In vitro evaluation}

\subsubsection{MSC isolation and characterization}

All experiments were carried out with MSCs obtained from rat bone marrow. Briefly, the bone marrow from the femur and tibia of 5 male Lewis rats $(200 \mathrm{~g})$ was flushed with sterile phosphate buffered saline (PBS; Spitalpharmazie, Inselspital Bern, Switzerland), centrifuged and resuspended in red blood cell lysis buffer (Gentra Systems Inc.; Minneapolis, USA). After 10 min incubation, samples were centrifuged, resuspended in fresh medium and seeded in culture flasks. MSCs were selected upon adherence and medium was removed after 2 days. The medium was then transferred into a new flask in order to further collect adherent cells.

Cell culture was performed under standard conditions on tissue treated polystyrene (TCPS; TPP Omnilab, Mettmenstetten, Switzerland and BD, Biosciences, San José, USA), at $37{ }^{\circ} \mathrm{C}$ and $5 \% \mathrm{CO}_{2}$ in a humidified incubator (Thermo Forma, Model 371, Thermo Fisher Scientific, Waltham, USA). MSCs were expanded in growth medium (Dulbecco's modified Eagle Medium, Gibco, Invitrogen, Carlsbad, USA) supplemented with $20 \%$ fetal bovine serum (FBS; PAA clone, Connectorate AG, Dietikon, Switzerland) and 1.25\% penicillin/ streptomycin solution $\left(\mathrm{P} / \mathrm{S} ; 100 \mu \mathrm{g} \mathrm{ml}^{-1}\right.$, Gibco, Invitrogen, Carlsbad, USA). MSCs were maintained in culture and expanded for 1 week. Medium was changed every second day. Accutase was used to detach the cells prior to culture on substrates for 1 week.

MSCs were characterized by fluorescence activated cell sorting (FACS; FACScan, BD, Biosciences, San José, USA) using PE-labelled anti CD90, FITC-labelled anti CD45 and PE-labelled anti CD31 (all $\mathrm{BD}$, Biosciences, San José, USA). Cells were $\mathrm{CD}^{(+)}(34.3 \%)$, $\mathrm{CD}_{4} 5^{(-)}(0 \%), \mathrm{CD} 31^{(-)}(0 \%), \mathrm{CD} 29^{(+)}(25.7 \%), \mathrm{CD} 44^{(+)}(42.9 \%), \mathrm{Sca} 1^{(-)}$ $(0 \%)$ and $\mathrm{cKit}^{(-)}(0 \%)$. MSCs retained their capacity to differentiate into adipocytes and cardiac troponin $\mathrm{C}^{(+)}$cells when cultured in appropriate differentiation media.

\subsubsection{Culture on the substrates}

Cell seeding on the substrates was accomplished according to previously established methods from our group [36]. Briefly, bottoms of 12-well culture dishes were coated with silicone (Sylgard-184 two component silicone, Sylgard, Dow Corning Corporation, Midland, USA). Patches of $15 \times 10 \times 0.1 \mathrm{~mm}$ were fixed by stainless steel minutiae insect pins (EntoSPHINX, Pardubice, Czech Republic) on the silicone coating and sterilized under UV light overnight. MSCs were seeded at a density of $2 \times 10^{6}$ cells per patch. A $200 \mu \mathrm{l}$ cell suspension was deposited at the surface of the patch and cells were allowed to adhere for $3 \mathrm{~h}$ prior to medium addition. Substrates were cultured for 7 days in growth medium prior to implantation.

Cell viability was assessed $24 \mathrm{~h}$ post-seeding and at the day of implantation with an MTT assay (3-(4,5-dimethylthiazol-2-yl)- 
2,5-diphenyltetrazolium bromide, Sigma-Aldrich, Buchs, Switzerland). Patches were incubated with $0.5 \mathrm{mg} \mathrm{ml}^{-1}$ MTT in growth medium for $2 \mathrm{~h}$. An intense blue staining confirmed viable cells. Further, a commercially available cell proliferation assay kit (CyQuant, Invitrogen, Carlsbad, USA) allowed for cell number quantification. Constructs were incubated in cell lysis buffer, sonicated (Sonopuls HD 2070/UW 2070, Bandelin electronic, Berlin, Germany), vortexed and centrifuged, followed by incubation with a DNA binding fluorescent agent (CyQuant GR dye solution). Quantification was accomplished spectrophotometrically (Infinite 200, Tecan Trading AG, Männedorf, Switzerland) at $480 \mathrm{~nm}$ excitation and $520 \mathrm{~nm}$ emission wavelengths.

SEM was carried out to investigate cell morphology. Prior to imaging, constructs were fixed in 4\% formaldehyde (Institute of Pathology, University Hospital Bern, Switzerland) and dehydrated in an ascending ethanol series and dried in hexamethyldisiloxane (Sigma-Aldrich, Buchs, Switzerland). Constructs were gold-sputtered and micrographs were acquired on a Hitachi S-4800 at $2 \mathrm{kV}$ acceleration voltage and $10 \mu \mathrm{A}$ current flow.

\subsection{In vivo evaluation}

All animals received humane care in compliance with the European Convention on Animal Care.

Surgical procedures were performed in accordance with the Swiss Animal Protection Law after permission was obtained from the State Veterinary Office, Bern, approved by the Swiss Federal Veterinary Office, Switzerland (BE 40/10). All surgical interventions were performed under isofluorane anesthesia. Efforts were made to diminish animal suffering; in particular, all animals received subcutaneous injection of $0.1 \mathrm{mg} \mathrm{kg}^{-1}$ Temgesic (Buprenorphine, $0.3 \mathrm{mg} \mathrm{ml}^{-1}$; ESSEX Chemie, Luzern, Switzerland) post-surgery.

\subsubsection{Model of MI}

As previously reported [4], cardiac patch evaluation was carried out in an established surgical model of MI. 41 female Lewis rats (Janvier, Le Genest, France), weighing $230 \mathrm{~g}$ were anesthetized with isoflurane and oxygen (5\% for induction and $2.5 \%$ for maintenance). Rats were placed on a warming pad of $37^{\circ} \mathrm{C}$ to avoid hypothermia during anesthesia and ventilated with 80 cycles $\mathrm{min}^{-1}$ (14-G IV cannula, Abbocath, Abbott, Sligo, Ireland; Small Animal Ventilator 683 Harvard Apparatus, Inc., Holliston, USA). For surgical induction of an MI, hearts were accessed through a left thoracotomy between the fourth and fifth interstitial space. After opening the pericardium, a permanent ligation of the left anterior descending coronary artery was performed (7/0 polypropylene suture, Ethicon, Inc., Somerville, USA), resulting in permanent blood restriction. 2 weeks post-infarction, animals with an assessed ejection fraction between 30\% and 65\% were randomized into three treatment groups, receiving either MSC-seeded cardiac patches (MSCPs, $n=11$ ), MSC-free cardiac patches (CPs, $n=11$ ) or a sham operation (sham, $n=14$ ). Treatment was applied via a second thoracotomy between the fifth and sixth interstitial space.

MSCPs or CPs were glued (Tisseel Fibrin sealant, Baxter, Deerfield, USA) cell-side down onto the myocardium. Fiber orientation of the patch was parallel to the longitudinal axis of the heart, from apex to aorta. Sham treated rats underwent a second thoracotomy without any applied treatment.

\subsubsection{Functional analysis}

Echocardiograms were recorded 2 weeks post-MI (pre-treatment) and 6 weeks post-infarction (post-treatment) by a wellexperienced cardiologist in a blinded manner. Briefly, rats were anesthetized with $2.5 \%$ isoflurane and placed on the left lateral position. Echocardiographs were recorded using a 9-11 MHz linear array transducer system (AcusonSequoia, Siemens, Inc., Malvern,
USA). LV M-mode measurements were performed to quantify internal diameters at systole and diastole and to calculate fractional shortening (FS) in percentage:

$$
\begin{aligned}
\mathrm{FS}(\%)= & \frac{[(\text { LV end-diastolic diameter }])-(\text { LV end-systolic diameter })}{(\text { LV end-diastolic diameter })} \\
& \times 100
\end{aligned}
$$

A two-dimensional (2-D) mode obtained from a long axis view was used to determine volume and ejection fraction (EF) using a biplane Simpson's method.

\subsubsection{Histological analysis}

Molecular mechanisms underlying repair of myocardial tissue were investigated immunohistologically. Infarct size, vascular density and immune response were assessed.

Hearts were excised and washed in PBS. A transversal cut was placed $5 \mathrm{~mm}$ from the apex. The lower part was embedded in optimal cutting temperature medium (OCT; Tissue Tek, Sakura, Alphen aan den Rijn, The Netherlands) and frozen over 2 methyl-butan vapour (Sigma-Aldrich, Buchs, Switzerland), cooled with liquid nitrogen (Carbagas, Gümligen, Switzerland). OCT embedded hearts were stored at $-80^{\circ} \mathrm{C}$.

Subsequently, hearts were cryosectioned on a Leica CM 3050S cryostat (Leica Biosystems $\mathrm{GmbH}$, Nussloch, Germany) at a slice thickness of $8 \mu \mathrm{m}$.

Fibrotic tissue was assessed based on Goldner staining. Briefly, cryosectioned hearts were thawed and air-dried and fixation was carried out in Bouin fixation solution overnight (glacial acetic acid, $36 \%$ formalin and picric acid; all Sigma-Aldrich, Buchs, Switzerland), followed by incubation in Weigert's Hematoxyline (Merck AG, Zug, Switzerland), Acid Fuchsin-Ponceau (Sigma-Aldrich, Buchs, Switzerland), Phosophomolybden acid Orange G (Merck AG, Zug Switzerland and Sigma-Aldrich, Buchs, Switzerland) and Lichtgrün (Sigma-Aldrich, Buchs, Switzerland).

Samples were dehydrated in an ascending ethanol series and mounted with Eukitt (EM Sciences, Hatfield, USA). Images were acquired on a Nikon Eclipse-2000 light microscopy (Nikon, Tokyo, Japan). The LV was manually traced on the digital image. The LV was selected and the right ventricle excluded from the picture. Using the colour recognition option of the software (Bersoft Image Analysis, Bersoft Technology and Software, Lunenburg, Canada), we obtained the area of the LV myocardium (red), the area of the LV cavity (white) and the area of the infarct (green). We also obtained the septum and scar thickness by averaging three distances measured from each wall. Relative scar thickness was calculated as scar thickness divided by septum thickness. Whole LV area was calculated by adding the area of the LV myocardium and LV cavity. Expansion index was calculated as follows [37]:

expansion index $=\frac{\text { LV cavity area/whole LV area }}{\text { relative scar thickness }}$

Whereas the percentage infarct size was calculated as

infarct size $(\%)=\frac{\text { infarct area }}{\text { LV myocardium area }} \times 100$

Measurements were accomplished and averaged based on nine cryosections of $n=9$ (MSCP), $n=11$ (CP) and $n=11$ (sham) respectively [38].

Immunohistological stainings were assessed on thawed, air dried, fixed (4\% formaldehyde) and permeabilized $(0.2 \%$ triton X100 in PBS Sigma-Aldrich, Buchs, Switzerland) cryosections. Nonspecific sites were blocked in $3 \%$ bovine serum albumin solution (BSA; Sigma-Aldrich, Buchs, Switzerland) prior to primary antibody incubation, followed by fluorescently labelled secondary 
antibody incubation. Quantitative histological analysis was accomplished on three cuts of $8 \mu \mathrm{m}$ thickness per sample and expressed as mean $\pm \mathrm{SD}$.

Vessel formation was assessed by von Willebrand factor (vWf) staining (anti vWf antibody, abcam, Cambridge) [39]. Constructs were counterstained with Hoechst (No 33258; Invitrogen, Molecular Probes, Carlsbad, USA) and mounted with Glycergel (Dako, USA). Vessels were counted manually based on light microscopy images and reported as number of vessels $\mathrm{mm}^{-2}$. Measurements were accomplished and averaged based on six cryosections of $n=3$ animals per group.

Inflammatory response was assessed based on CD68 staining for macrophages [40]. Constructs were incubated with anti-CD68 antibody (MCA341, Abd Serotec, Oxford, UK), followed by fluorescently labelled antibody (Alexa 555 conjugated antibody, Invitrogen, Carlsbad, USA) and counterstaining with Hoechst. CD68 ${ }^{(+)}$ cells were automatically counted with NIS elements software (Nikon, Tokyo, Japan) based on fluorescent images, colour and size recognition in a blinded manner. Results are reported as number of $\mathrm{CD}^{(+)}$cells $\mathrm{mm}^{-2}$. Measurements were accomplished and averaged based on three cryosections of $n=3$ animals per group.

\subsubsection{Chromosome Y tracking}

Upon heart excision, a distal section containing a part of the infarcted region and the biograft (MSCP, $n=3$ ) or the infarcted region and the patch $(\mathrm{CP}, n=4)$ was embedded in RNA-later (Qiagen AG, Basel, Switzerland) and gradually frozen to $-80^{\circ} \mathrm{C}$. Chromosome $\mathrm{Y}$ analysis (SRY1 gene tracking) was performed by Microsynth, Balgach, Switzerland. Genomic DNA extraction was accomplished with a Qiamp-Kit (Qiagen AG, Basel, Switzerland), followed by reverse transcription polymerase chain reaction (RTPCR) (Taqman-Universal Mastermix, Applied Biosystems). Probe, forward and reverse primer were respectively CTGCTCCTACC TATGCCAACACTCC (probe), CCTGTGATAGGTAATCTCATG (forward) and CACACTACACATCCTTACAC (reverse).

\subsection{Statistical analysis}

Results are presented as mean \pm standard deviation. Differences between pre- and post-treatment (data of echocardiography) were assessed by a non-parametric paired signed-rank Wilcoxon test, values of histological quantification by a Kruskal-Wallis test (SPSS for Windows; version 17.0; SPSS Inc, Chicago, USA). Values were accepted as significantly different for $P<0.05$.

\section{Results}

\subsection{Characterization and in vitro evaluation of plasma-coated electrospun substrates}

To provide an adequate microenvironment for cell adhesion and growth, it is important to control the surface chemistry and architecture of the matrix. We processed PCL by electrospinning to produce fibres that displayed diameters of $3.3 \pm 0.8 \mu \mathrm{m}$. By spinning onto a rotating collector, we obtained an anisotropic matrix of parallel oriented fibres (Fig. 1A). The oxygen functional hydrocarbon coating (a-C:H:O), superimposed on the surface of the fibres by plasma polymerization, was validated by XPS analysis. The high $\mathrm{CO}_{2} / \mathrm{C}_{2} \mathrm{H}_{4}$ ratio of $6: 1$ supports plasma chemical formation of oxygen-containing hydrocarbon species within the gas phase, showing rather low sticking probabilities [41]. Therefore, good penetration of the complex fibrous structure by the film-forming species is enabled, yielding a coating thickness of several nanometres on the fibres.
The composition of oxygen functional groups was confirmed and characterized by use of high resolution C1s spectra (Fig. 1C) showing an $\mathrm{O} / \mathrm{C}$ ratio of $\sim 0.35$ [35]. The high amount of ester groups (COOR) obtained indicates cross-linking of the ultrathin plasma polymer layer [42].

We further evaluated the consequential modification in surface wettability and showed that oxygen-functionalized coatings greatly reduced the static water contact angle on the electrospun fibres from $114 \pm 13^{\circ}$ to complete wicking conditions. The corresponding drop absorption within 1 to $10 \mathrm{~s}$ confirmed the high hydrophilicity of plasma functionalized electrospun matrices.

Using a standardized procedure [36], MSCs were seeded on the substrates and cultured for 7 days. MSCs spread on the surface of the matrix, following the parallel fibre orientation, forming a homogeneous layer (Fig. 1B). MTT analysis confirmed MSC viability, indicated by intense blue staining (data not shown). DNA quantification revealed a number of $2 \pm 0.9 \times 10^{6}$ cells per patch, corresponding to a density of $1.33 \times 10^{4}$ cells $\mathrm{mm}^{-2}$.

In order to test the hypothesis that the matrix and the matrix seeded with cells would provide different mechanical support to the injured heart, we compared the mechanical properties of the cell-free $\mathrm{CP}$ to the MSCP, both pre-incubated in culture medium. $E$ moduli were $18.3 \pm 0.9 \mathrm{MPa}$ and $16.1 \pm 3.9 \mathrm{MPa}$ for $\mathrm{CP}$ and MSCP, respectively. Representative stress-strain curves are displayed in Fig. 1D. Our data demonstrated that both patches presented identical mechanical properties in terms of elasticity and plasticity.

\subsection{Implantation and in vivo evaluation of cardiac patches}

Following in vitro evaluation, we implanted MSC seeded and cell-free patches in a rodent model of a chronic MI. MI was induced by permanent ligation of the left anterior descending artery (LAD).Two weeks post-MI, the patches were glued to the surface of the necrotic area. Animals received either an $\operatorname{MSCP}(n=11)$ or a cell-free CP $(n=11)$. 14 rats served as control and received no treatment post-MI (sham group). In addition, hearts of three healthy animals were excised as control group (control). The mortality rate was 5\%; animal death occurred after LAD ligation during the first surgery. All animals survived the second surgery and patch implantation.

Implantation of the cardiac patch was performed directly on beating hearts. The mechanical integrity of the patch and optimized handling allowed for safe and efficient fixation. A thin layer of Tisseel glue ${ }^{\circledR}$ and gentle positioning of the patch on the myocardium, followed by careful placing with forceps, guaranteed a full coverage and adhesion to the necrotic tissue (Fig. 2A). Only two animals were not included in the study due to technical difficulties during implantation; i.e. the patch was folded during implantation and was not correctly placed to the myocardium. Four weeks postimplantation, MSCPs or CPs were well adherent to the myocardium and presented minor adhesion to the surrounding tissue (Fig. 2C).

\subsubsection{MSC-seeded cardiac patches stabilized cardiac function and prevented $L V$ dilatation}

We used M mode and 2-D mode echocardiography to assess, respectively, fractional shortening (\% FS) and ejection fraction (\% $\mathrm{EF}$ ), both pre- and post-treatment. Control animals without MI displayed EF and FS values of $74 \pm 4 \%$ and $44 \pm 3 \%$, respectively. Echocardiography performed two weeks post-LAD ligation confirmed the presence of an established MI, as indicated by a reduced cardiac function (EF of $49 \pm 9 \%$ and an FS of $22 \pm 4 \%$; $P<0.0001$ ). 4 weeks later, as presented in Fig. 3, cardiac function was further reduced in sham and CP-treated animals. As demonstrated in Fig. 3, delta $\mathrm{EF}$ and delta FS (percentage point (pp) difference between postand pre-treatment) were $-10 \pm 9 \mathrm{pp}(P=0.006)$ and $-6 \pm 6 \mathrm{pp}$ $(P=0.010)$ in $\mathrm{CP}$ treated animals; $-7 \pm 10 \mathrm{pp}(P=0.011)$ and 


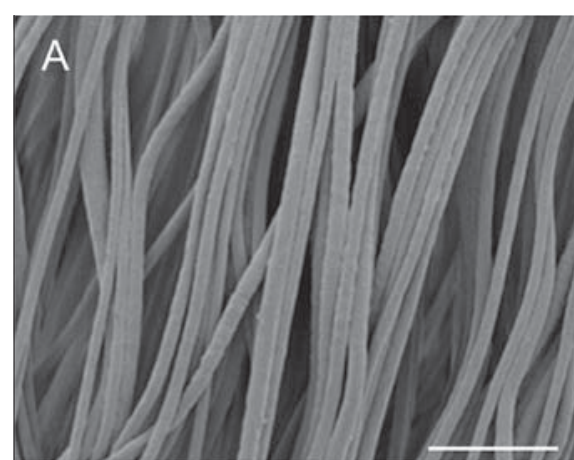

C

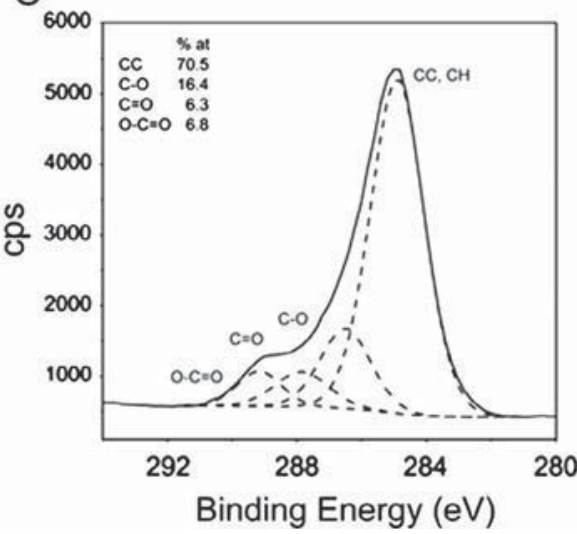

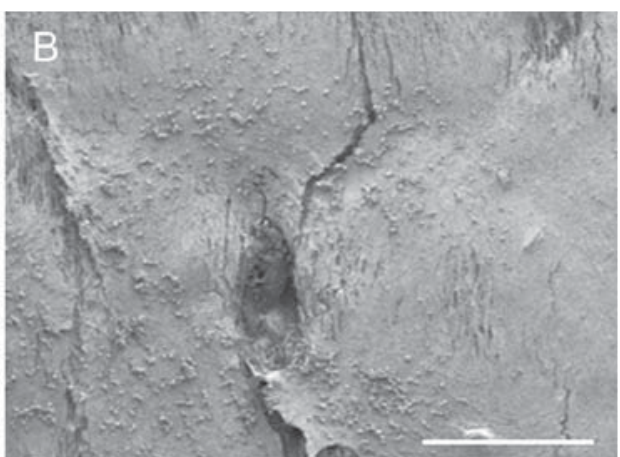

D

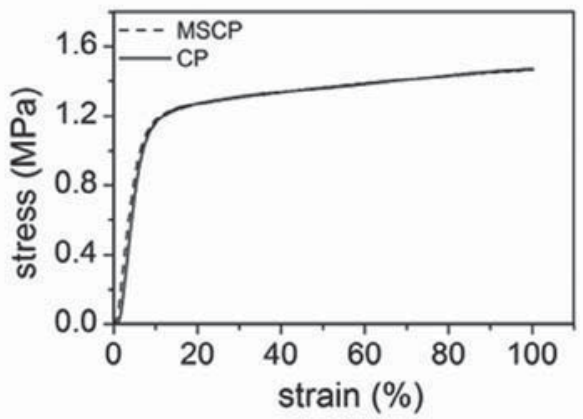

Figure 1. Substrate characterization. SEM images of (A) cell-free and (B) cell-seeded fibrous substrates. Fibre diameter was $3.3 \pm 0.8 \mu$ m. MSCs adhered well to the substrate and formed a homogeneous layer. Scale bars: (A) $10 \mu \mathrm{m}$, (B) $100 \mu \mathrm{m}$. (C) Representative C1s spectrum. XPS analysis confirmed the formation of an oxygen functional hydrocarbon layer, represented by carbonyl, carboxyl and hydroxyl groups. (D) Representative stress-strain curves, indicating identical mechanical properties of cell-seeded (MSCP) and cell-free (CP) cardiac grafts.
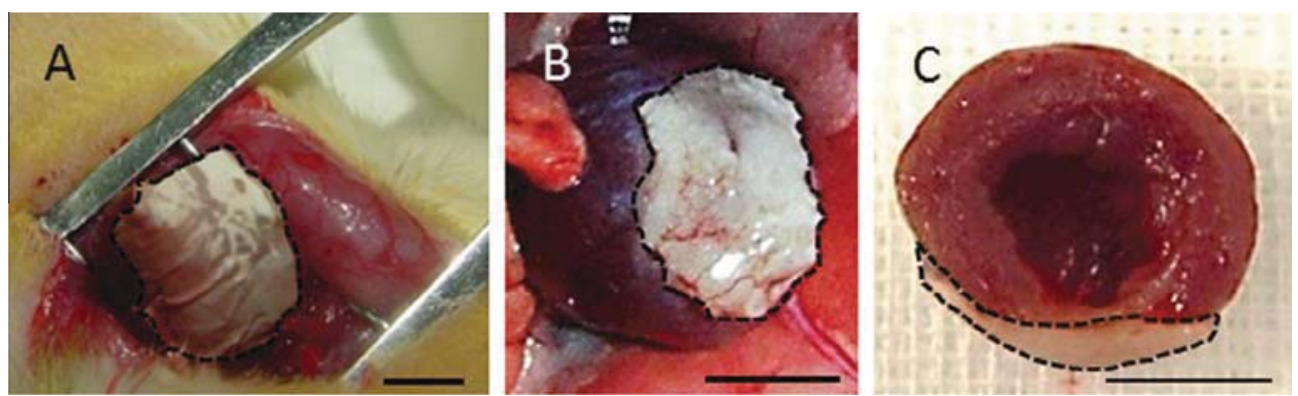

Figure 2. Photographs of MSCP implantation and excised hearts 4 weeks post-implantation. (A) The patch was placed on the beating heart. The ischemic area was well covered. (B) MSCP 4 weeks post-implantation. Neo-vessels are apparent on the surface of the MSCP. (C) Transversal cut of an excised heart. The patch is strongly adherent to the LV wall. Patch contours are represented in dashed lines. Scale bar: $5 \mathrm{~mm}$.

$-5 \pm 6 \mathrm{pp}(P=0.010)$ in sham treated animals. In contrast, MSCP treatment induced a stabilization in cardiac function, represented by a delta $\mathrm{EF}$ of $-4 \pm 10 \mathrm{pp}(P=0.285)$ and a delta FS of $-2 \pm 7 \mathrm{pp}$ $(P=0.182)$. These changes corresponded to the following relative percent decreases (calculated as (difference between post-and pre-treatment) $\times 100 /$ pre-treatment): respectively, a decrease of $13 \%$ of $\mathrm{EF}$ and $15 \%$ of $\mathrm{FS}$ in the sham group, $20 \%$ and $25 \%$; in the CP group and $6 \%$ for both EF and FS in the MSCP group.

LV dimensions (diameter and volume) obtained by echocardiography for healthy animals were, respectively, $3.1 \pm 0.3 \mathrm{~mm}$ and $0.10 \pm 0.00 \mathrm{ml}$ at the end of systole and $5.6 \pm 0.2 \mathrm{~mm}$ and $0.41 \pm 0.04 \mathrm{ml}$ at the end of diastole. LAD ligation induced, after 2 weeks, an increase in LV diameter and volume at the end of systole $(5.5 \pm 0.8 \mathrm{~mm}$ and $0.40 \pm 0.16 \mathrm{ml}$, respectively; $P<0.0001)$ and at the end of diastole $(7.0 \pm 1.3 \mathrm{~mm}$ and $0.83 \pm 0.29 \mathrm{ml}$, respectively; $P<0.0001$ ).

4 weeks post-treatment, diastolic and systolic diameters and volumes were further recorded. At the end of diastole, we measured significant increases in LV diameter in CP $(+0.9 \pm 1 \mathrm{~mm}$, $P=0.02)$ and sham $(+0.8 \pm 0.9 \mathrm{~mm}, P=0.006)$ treated animals (Fig. 4). Conversely, we observed that LV diameter of MSCP treated animals remained statistically similar for pre- or post-treatment $(+0.3 \pm 0.8 \mathrm{~mm}, P=0.212)$. In line, the LV end diastolic volume was significantly increased for $\mathrm{CP}$ or sham treated animals and stabilized in MSCP treated animals.

Regarding LV diameters measured at the end of systole, an increase of $+1.3 \pm 11 \mathrm{~mm} \quad(P=0.007)$ and $+1.0 \pm 0.9 \mathrm{~mm}$ $(P=0.003)$ was observed in $\mathrm{CP}$ and sham treated groups, respec- 

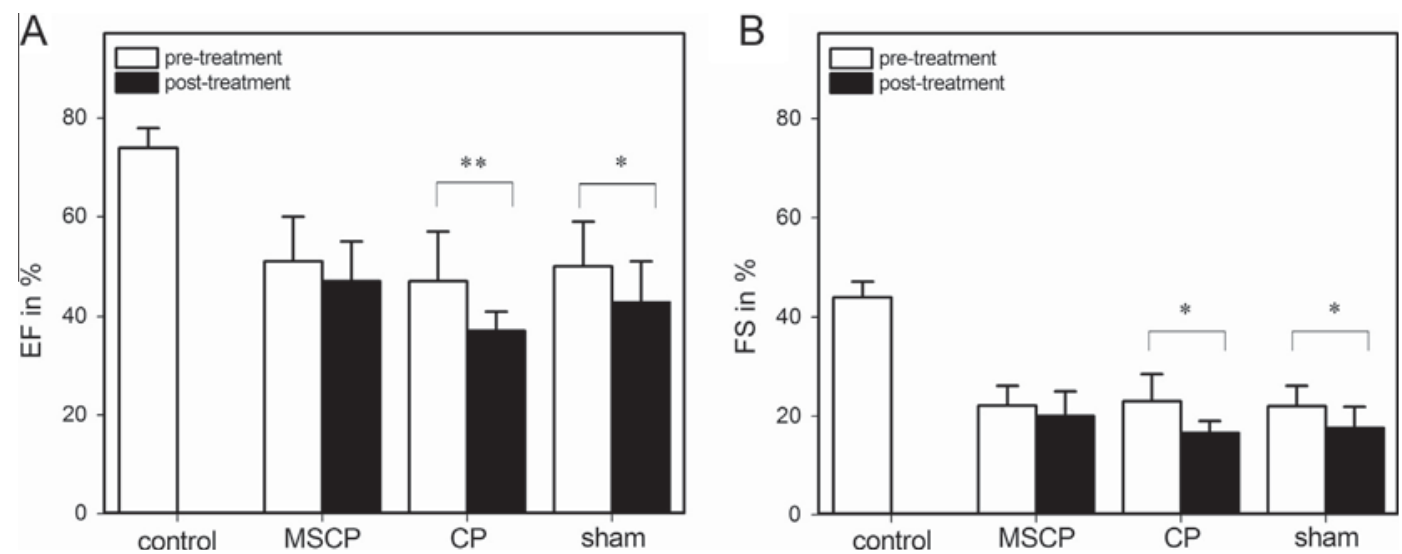

Figure 3. Cardiac function assessed by echocardiography. (A) ejection fraction (EF) and (B) fractional shortening (FS) pre- and post-treatment. EF was significantly reduced in $\mathrm{CP}$ and sham treated animals over time. Similarly, FS was significantly decreased in these groups. In MSCP treated animals, EF and FS were stabilized over time. "Control" indicates EF and FS, respectively, of healthy rats without MI $\left({ }^{*} P<0.05,{ }^{* *} P<0.01\right.$, pre- vs. post-treatment).
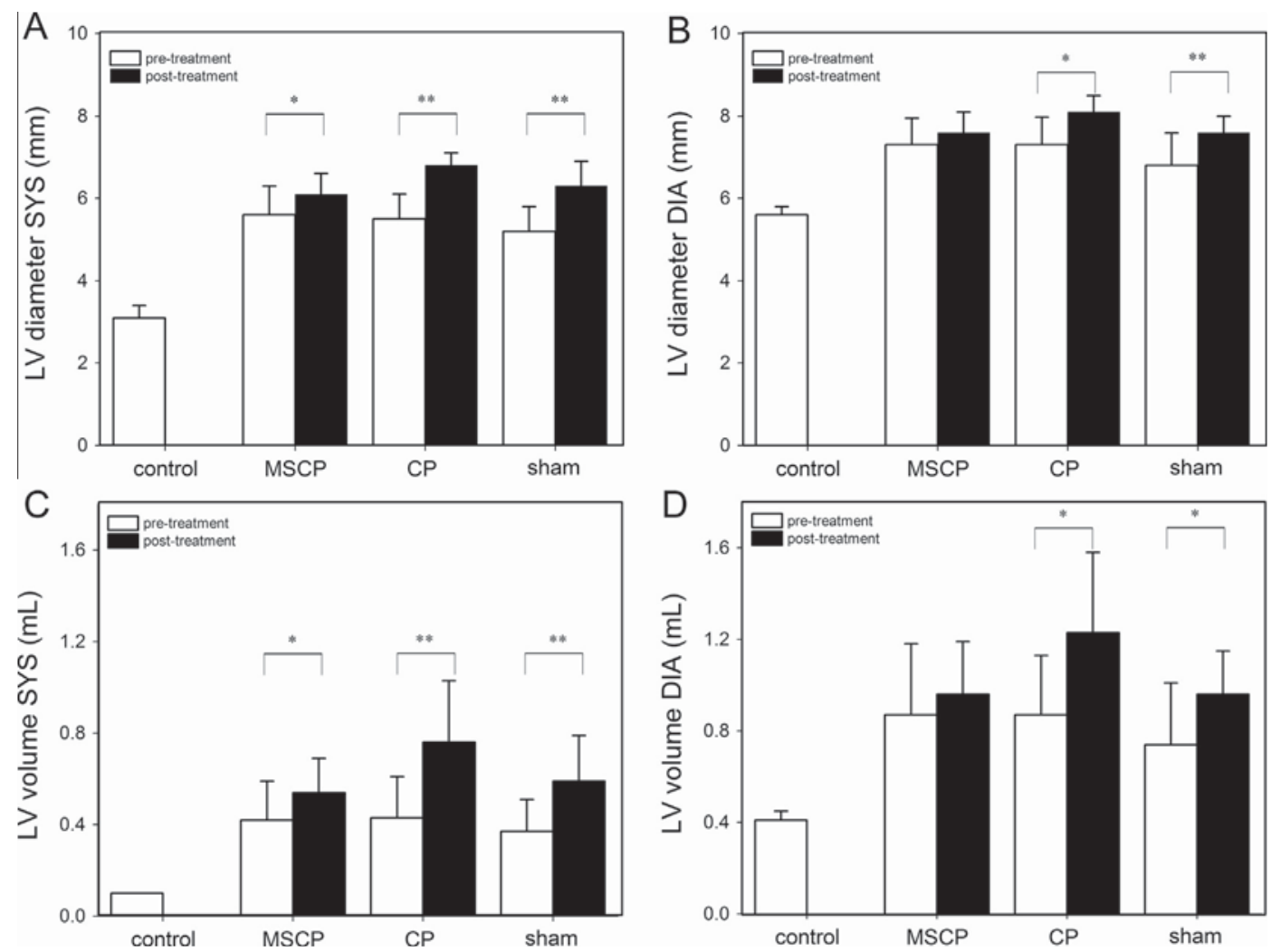

Figure 4. LV diameter and volume at the end of systole (A, C) or at the end of diastole (B, D). End systolic LV diameter was significantly elevated in all groups. End diastolic diameter was stabilized in MSCP treated animals, but significantly elevated in control groups. In line, LV volumes during systole were significantly increased in all groups, whereas LV volume during diastole was stabilized in MSCP treated animals $\left({ }^{*} P<0.05,{ }^{* *} P<0.01\right.$, pre- vs. post-treatment).

tively. A significant smaller $(+0.4 \pm 0.6 \mathrm{~mm}, P=0.021)$ increase was observed in the MSCP group (Fig. 4).

\subsubsection{Histological evaluation of implanted patches}

Vascularization of implants presents a necessary prerequisite to provide adequate nutrient and oxygen supply to the implanted cells. Macroscopic observations showed that cardiac patches were covered with a thin layer of connective tissue with visible vascularization (Fig. 2B). Post-excision, we examined the number and density of vessels present within the patches by an anti-von Willebrand factor (vWf) staining, a marker of endothelial cells (Fig. 5). The results revealed that the vessel density within the patch was comparable for both MSCP and CP $(5 \pm 0.5$ and $5 \pm 3$ vessels $\mathrm{mm}^{-2}$, respectively). Results are displayed in Table 1 .

Induction of MI is associated with the stimulation of an inflammatory response, represented by the recruitment of macrophages within the ischemic area. We examined if cardiac patch treatment altered macrophage recruitment using anti-CD68 immunostaining, a macrophage surface marker. Results showed that $\mathrm{CD} 68^{(+)}$macrophages invaded the fibrotic area of hearts in all groups. In $\mathrm{CP}$ and MSCP treated animals, we measured a significantly higher number of $\mathrm{CD} 8^{(+)}$cells compared with sham treated animals (Fig. 6). On healthy, non-infarcted hearts that received patch treatment (no MI with $\mathrm{CP}), \mathrm{CD} 68^{(+)}$macrophages were absent. 

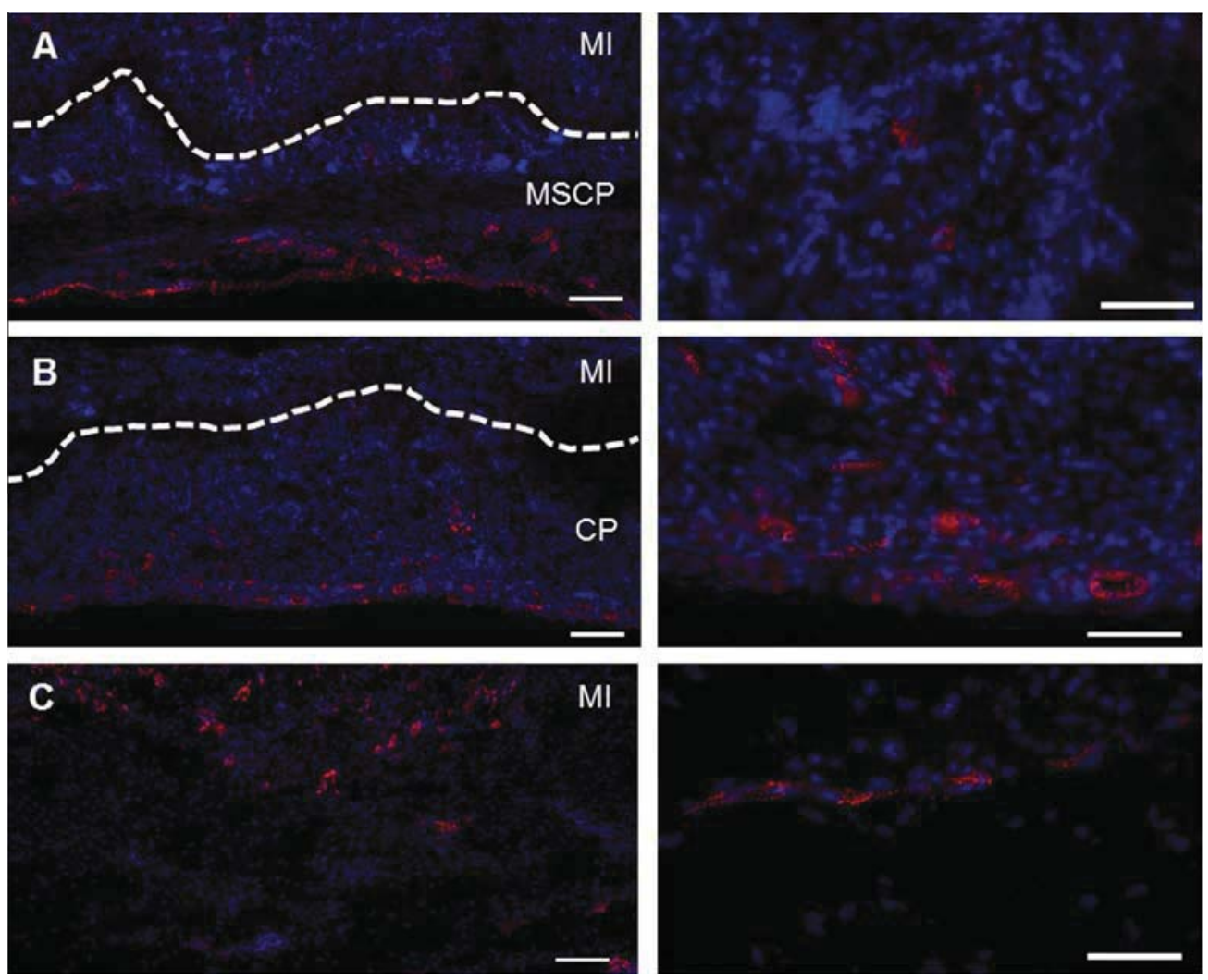

Figure 5. Representative images of vWf ${ }^{(+)}$stained vessels in (A) MSCP, (B) CP and (C) sham treated hearts at low (10×, left-hand side) and high (40×, right-hand side) magnification. Nuclei are stained in blue. The white line represents the middle of the cardiac patch, where no cells were located. Highly vascularized connective tissue was formed around the implants. Vessel ingrowth was found in MSCP and CP. Scale bars: $100 \mu \mathrm{m}$ (left-hand side) and $50 \mu \mathrm{m}$ (right-hand side), respectively.

Table 1

Histological evaluation of vascularization. Number of vessels per $\mathrm{mm}^{2}$.

\begin{tabular}{lccll}
\hline & $\begin{array}{l}\text { MSCP } \\
(n=4)\end{array}$ & $\begin{array}{l}\text { CP } \\
(n=4)\end{array}$ & $\begin{array}{l}\text { Sham } \\
(n=4)\end{array}$ & $\begin{array}{l}\text { Control } \\
(n=3)\end{array}$ \\
\hline $\begin{array}{l}\text { Scar tissue } \\
\text { Scaffold }\end{array}$ & $12 \pm 1$ & $17 \pm 8$ & $9 \pm 2$ & \\
$\begin{array}{l}\text { Non-ischemic } \\
\text { tissue }\end{array}$ & $5 \pm 0.5$ & $5 \pm 3$ & & $10 \pm 1$ \\
\hline
\end{tabular}

Vessels were counted manually based on light microscopy images.

Rapidly after MI and consequent inflammation, the recruitment of myofibroblasts induced the formation of a fibrotic area. We evaluated if the treatment affected the healing process and assessed, 6 weeks following the LAD ligation, the percentage of fibrotic area and the degree of infarct expansion. Characterization of the fibrotic area and the scar dimensions were performed by image analysis of Goldner stained cryosections (Fig. 7). Fibrotic area, relative scar thickness and expansion index were statistically identical in each group (Table 2).

\subsection{MSC seeded matrices allowed cell retention at the site of the infarction}

We evaluated the presence of implanted cells 4 weeks postimplantation. Sex-mismatched implantation of MSC and PCR analysis on myocardial biopsies from the necrotic area allowed for chromosome Y identification. The presence of implanted MSCs was proven by a normalized Ct value of SRY of $0.86 \pm 0.76$ in MSCP treated animals. In the $\mathrm{CP}$ group, detection of chromosome $\mathrm{Y}$ was below the detection limit and confirmed the absence of male MSCs as expected.

\section{Discussion}

In the present study, we demonstrated, and to the best of our knowledge for the first time, that plasma-functionalized electrospun PCL matrices represent a rapid, safe and efficient approach for epicardial delivery of MSC.

Myocardial cell therapy aims at counteracting MI consequences such as ventricular dilatation and remodelling by promoting endogenous tissue repair and regeneration. Up to now, a series of research work has demonstrated positive effects of cell therapy on reduction of cardiomyocyte necrosis, induction of angiogenesis and activation of host stem cell recruitment via the secretion of paracrine factors [43]. The clinical benefit of intramyocardial injection of autologous MSCs has also been increasingly reported [5]. However, issues such as the optimal mode of cell delivery remain open and represent important challenges to consider in order to improve outcomes of cardiac cell therapy. Tissue engineering approaches have gained increasing interest for controlled delivery of cells. In particular, it allows monitoring cell adhesion to the scaffold as well as implanting cells to defined and extended areas of the damage myocardium.

Cell adhesion and cell-biomaterial interaction is governed by material surface properties. We hereby provide evidence that incorporating oxygen functional groups to the matrix provided an adequate substrate for MSC culture. Accordingly, we have previously reported that oxygen functional groups improve the biointerface by reducing the scaffold hydrophobicity and enhancing cell adhesion of skeletal muscle cells (C2C12) and cardiogenic embryonic stem cells [16,44].

Furthermore, we showed that our matrix allowed the retention of MSCs four weeks post-epicardial implantation. Using RT-PCR, we identified the presence of implanted male MSCs in biopsies 

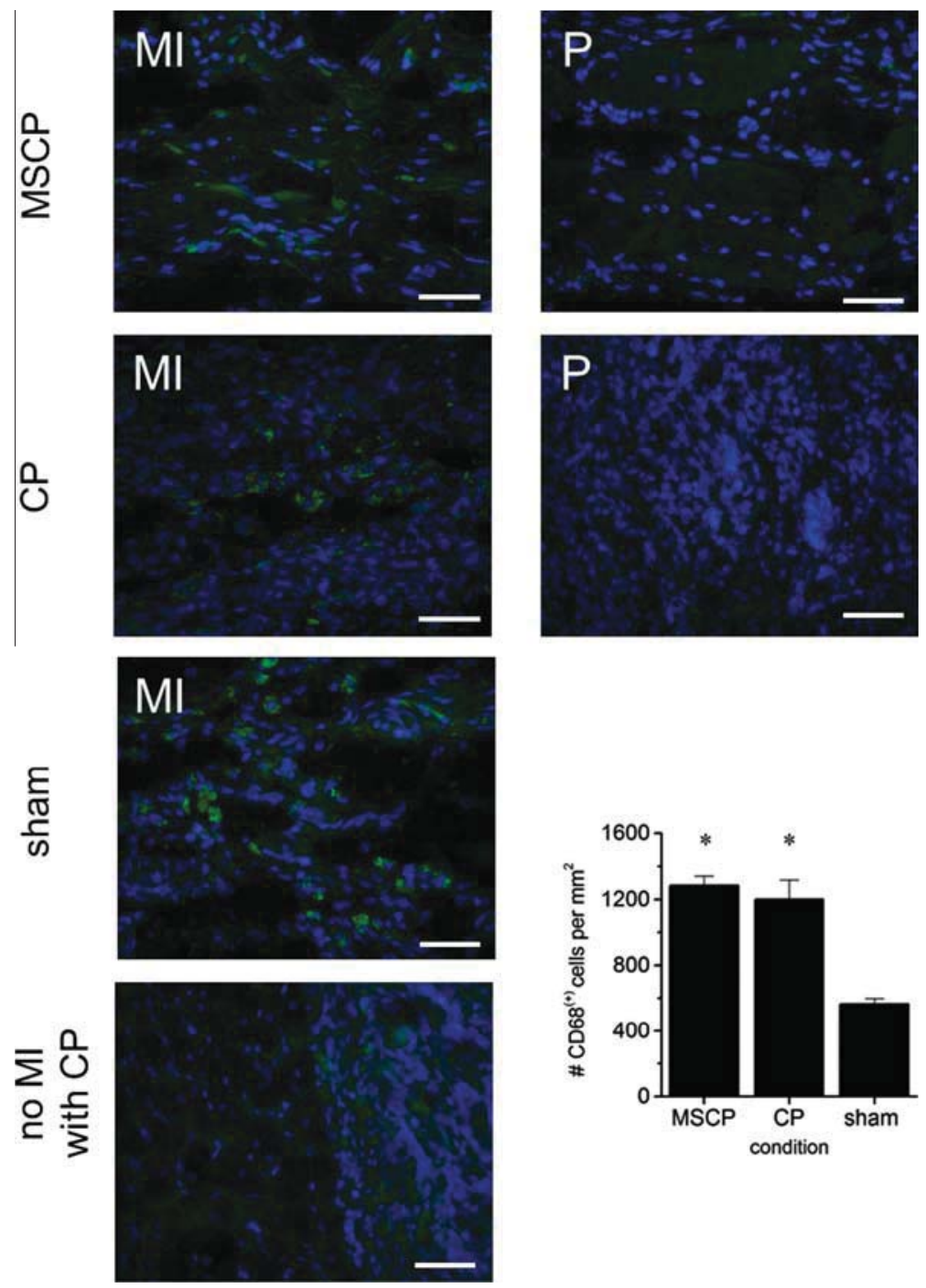

Figure 6. Macrophage invasion was quantified based on anti CD68 staining (green, nuclei stained in blue). "Control" indicates animals without MI where a cell-free cardiac patch was applied. An increased number of $\mathrm{CD}_{6} 8^{(+)}$cells was found in the scar tissue of MSCP or CP treated animals, compared with sham operated animals $\left({ }^{*} P<0.05\right)$. No macrophage invasion was found on healthy hearts that received CP implantation. Green stainings in the control group are artifacts and do not co-localize with nuclei staining and were therefore not identified as $\mathrm{CD}_{68} 8^{(+)}$cells. MI: picture taken in the area of myocardial infarction. P: picture taken from the implanted CP or MSCP. Macrophages were predominantly located within the infarcted tissue, not invading the implant. Scale bar: $10 \mu \mathrm{m}$.

composed of myocardium and implanted construct. Furthermore, this highly sensitive and specific technique confirmed the absence of Y chromosomes in the CP group. Nevertheless, quantification of surviving cells and their localization was not aimed in the current study and would require other specific approaches.

Biocompatibility of the constructs can be modified by chemical and architectural properties that modulate immune response and macrophage invasion. It has been reported that hydrophilic implants were generally better tolerated by the host [45]. Moreover, fibrous, parallel oriented substrates were shown to reduce pro-inflammatory cytokine production when compared to 2-D films or randomly oriented fibres of the same material [46]. In our current study, we demonstrated that a plasma-coated, hydrophilic cardiac patch presenting parallel oriented fibres does not trigger macrophage invasion when implanted on healthy rat hearts, revealing thus the immune-tolerance of this patch. In our MI model, however, macrophage invasion was significantly increased in both MSCP and CP treated animals as compared to sham treated animals. This indicates that in response to MI, the immune response initially triggered by the ischemic injury was modulated by MSCP or CP implantation. Additionally, other parameters such as fibrotic area and scar expansion remained similar in all the groups. Taking together, our results suggest that our scaffold may play an active role in post-MI inflammation process. However, this inflammation response persisting for 4 weeks post-MI in treated groups was not associated with increased fibrosis. Therefore, further investigation will be necessary to define the role of this prolonged inflammation in the balance between reparative vs. reactive fibrosis of the myocardium.

Infarction development is largely variable between animals; we therefore compared cardiac function of pre- and post-treatment to evaluate therapeutic efficacy. This design setting is similar to the clinical reality and inter-patient variability. We demonstrated a stabilization of the heart function in MSCP treated animals compared to a loss in cardiac function in untreated animals. A stabilized cardiac function will limit the progression toward heart failure. In addition, LV dilatation usually occurred during remodelling of the left ventricle after MI. It represents a strong prognostic determinant and is closely related to the incidence of heart failure. We provide evidence of attenuation of post-MI dilatation following 


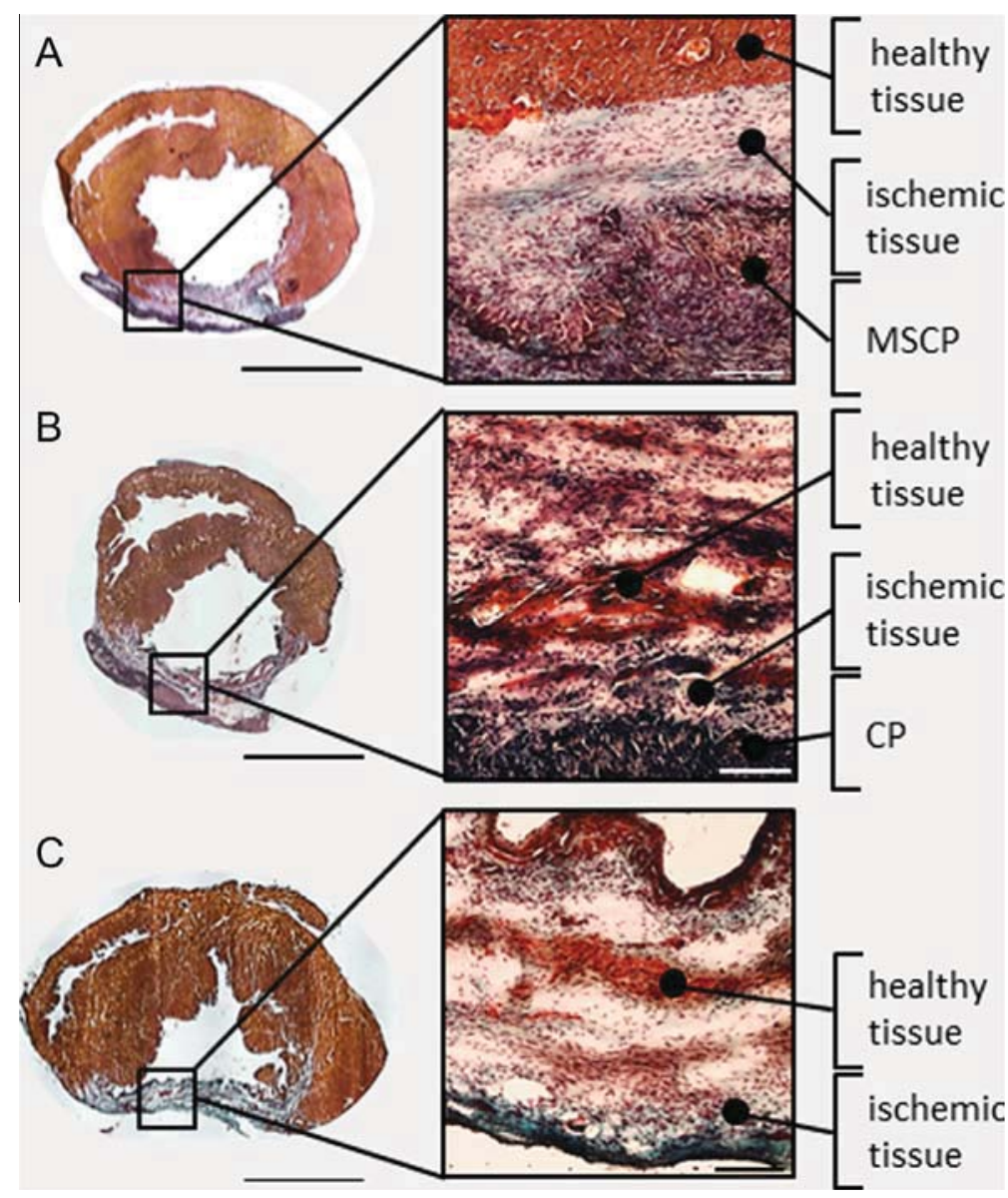

Figure 7. Goldner stained transversal heart sections. In blue, the fibrotic scar tissue is apparent, whereas the brown colour represents the remote tissue. The epicardially implanted patch is visible at the bottom of the image. Representative images of (A) MSCP, (B) CP and (C) sham treated animals. Scale bar: 5 mm and $100 \mu$ m, respectively.

Table 2

Parameters of LV geometry, assessed based on colour recognition on Goldner stained cryosections.

\begin{tabular}{lrrr}
\hline & MSCP $(n=9)$ & CP $(n=11)$ & Sham $(n=11)$ \\
\hline Scar thickness (mm) & $1.2 \pm 0.4$ & $1.4 \pm 0.3$ & $1.4 \pm 0.4$ \\
Area $_{\text {scar }}\left(\mathrm{mm}^{2}\right)$ & $7.0 \pm 2.8$ & $8.9 \pm 2.1$ & $8.2 \pm 1.4$ \\
Relative scar size (\% scar/LV) & $15.9 \pm 5.9$ & $20.8 \pm 4.5$ & $19.1 \pm 5.1$ \\
Expansion index* & $0.5 \pm 0.2$ & $0.4 \pm 0.2$ & $0.4 \pm 0.1$ \\
\hline
\end{tabular}

expansion index $=\frac{\text { LV cavity area/whole Lv area }}{\text { relative scar thickness }}$.

MSCP treatment. In contrast, remodelling after MI progressively leads to systolic expansion and cardiac dilatation as expected in the sham group. Similarly, increased LV diameter and volume, during both systole and diastole, clearly indicates a progressive cardiac dilatation after CP treatment. Therefore, we demonstrated that a plasma-functionalized electrospun matrix alone has no therapeutic effect. Our results suggest that the implanted matrix alone does not provide a sufficient mechanical constrain that may stabilize the heart function. In agreement, a recent study by Rane et al. [47] demonstrated that a passive myocardium structure reinforcement after synthetic polymer injection is insufficient for cardiac function stabilization. Both MSCP and CP presented similar mechanical properties; accordingly the mechanical girding effect could be excluded to explain the observed therapeutic effect following MSCP treatment.

The observed functional benefit corroborates previous studies including ours showing a reduced LV dilatation and stabilized cardiac function when biomaterials such as porous, solvent-casted or particle leached substrates of poly(glyocolic-co-caprolactone), poly(lactic-co-caprolactone) or polyurethane hydrogel matrices were implanted together with MSCs $[9,10,48-50]$ or skeletal myoblasts $[4,51]$.The main advantages of the current patch design rely on its mechanical integrity and its very thin nature necessary for an adequate positioning on the beating heart that remained stable for at least 4 weeks. Furthermore, characteristics of our matrix, such as a versatile and cost-efficient production and functionalization technology, as well as high potential for custom-tailored and tissue-specific modification, guarantee straightforward scaling up of the biograft. Pilot plants of electrospinning devices as well as plasma polymerization reactors are commercially available and pave the way to a successful transfer to industry. The importance of MSCs for treatment efficacy has been underlined in this study. In parallel acellular patches provided no beneficial effect. The study, however, also presents certain limitations. Cell tracking, viability and potential differentiation 4 weeks post-implantation remain to be addressed in future studies. A mechanistic approach including evaluation of cell therapy on cardiac metabolism will also be investigated and will be necessary to move towards efficient and fine-tuned clinical application.

\section{Conclusion}

We provide evidence for a beneficial effect of an MSC-seeded plasma-coated PCL graft on cardiac function in a rodent model of MI. Importantly, we demonstrated that the designed patch presents adequate chemical properties and mechanical integrity to allow epicardial implantation and cell delivery without signs of 
chronic inflammation. The optimized techniques of electrospinning and plasma polymerization allow for translational research and a potentially attractive transfer to the industry due to the use of convertible cost-effective procedures. Nevertheless, our findings warrant further thorough evaluation of the designed patch, particularly investigating the underlying mechanisms of cardiac repair.

\section{Acknowledgements}

The authors would like to acknowledge funding from SNF Grant 122334 and the Inselspital, Bern. We are also thankful to Prof. Philippe Zysset and Alexander Bürki, Institute for Surgical Technology \& Biomechanics, University of Bern, for stress-strain measurements. We would like to thank Céline Fouassier, Brigitta Gahl and Laura Seidel, Department of Cardiovascular Surgery, University Hospital Bern, for MSC isolation and culture, statistical analyses and English revision, respectively.

\section{Appendix A. Figures with essential colour discrimination}

Certain figures in this article, particularly Figs. 2 and 5-7, are difficult to interpret in black and white. The full color images can be found in the on-line version, at 10.1016/j.actbio.2014.01.006

\section{Appendix B. Supplementary data}

Supplementary data associated with this article can be found, in the online version

\section{References}

[1] Fraccarollo D, Galuppo P, Bauersachs J. Novel therapeutic approaches to postinfarction remodelling. Cardiovasc Res 2012;94:293-303.

[2] Abdelwahid E, Siminiak T, Guarita-Souza LC, Teixeira de Carvalho KA, Gallo P, Shim W, et al. Stem cell therapy in heart diseases: a review of selected new perspectives, practical considerations and clinical applications. Curr Cardiol Rev 2011;7:201-12.

[3] Martin-Rendon E, Brunskill S, Doree C, Hyde C, Watt S, Mathur A, et al. Stem cell treatment for acute myocardial infarction. Cochrane Database Syst Rev 2008; 4 art. no. CD006536.

[4] Giraud MN, Flueckiger R, Cook S, Ayuni E, Siepe M, Carrel T, et al. Long-term evaluation of myoblast seeded patches implanted on infarcted rat hearts. Artif Organs 2010;34:E184-92.

[5] van der Spoel TIG, Jansen of Lorkeers SJ, Agostoni P, van Belle E, Gyoengyoesi M, Sluijter JPG, et al. Human relevance of pre-clinical studies in stem cell therapy: systematic review and meta-analysis of large animal models of ischaemic heart disease. Cardiovasc Res 2011;91:649-58.

[6] Simpson D, Liu H, Fan T-HM, Nerem R, Dudley Jr SC. A tissue engineering approach to progenitor cell delivery results in significant cell engraftment and improved myocardial remodeling. Stem Cells 2007;25:2350-7.

[7] Hamdi H, Furuta A, Bellamy V, Bel A, Puymirat E, Peyrard S, et al. Cell delivery: intramyocardial injections or epicardial deposition? A head-to-head comparison. Ann Thorac Surg 2009;87:1196-204.

[8] Giraud MN, Guex AG, Tevaearai HT. Cell therapies for heart function recovery: focus on myocardial tissue engineering and nanotechnologies. Cardiol Res Pract 2012;2012. Article ID 971614, 10 pages.

[9] Piao H, Kwon J-S, Piao S, Sohn J-H, Lee Y-S, Bae J-W, et al. Effects of cardiac patches engineered with bone marrow-derived mononuclear cells and PGCL scaffolds in a rat myocardial infarction model. Biomaterials 2007:28:641-9.

[10] Jin J, Jeong SI, Shin YM, Lim KS, Shin HS, Lee YM, et al. Transplantation of mesenchymal stem cells within a poly(lactide-co-epsilon-caprolactone) scaffold improves cardiac function in a rat myocardial infarction model. Eur J Heart Fail 2009;11:147-53.

[11] Chi N-H, Yang M-C, Chung T-W, Chen J-Y, Chou N-K, Wang S-S. Cardiac repair achieved by bone marrow mesenchymal stem cells/silk fibroin/hyaluronic acid patches in a rat of myocardial infarction model. Biomaterials 2012;33:5541-51.

[12] Karam J-P, Muscari C, Montero-Menei CN. Combining adult stem cells and polymeric devices for tissue engineering in infarcted myocardium. Biomaterials 2012;33:5683-95.

[13] Holladay CA, Duffy AM, Chen X, Sefton MV, O'Brien TD, Pandit AS. Recovery of cardiac function mediated by MSC and interleukin-10 plasmid functionalised scaffold. Biomaterials 2012;33:1303-14.
[14] Fujimoto KL, Tobita K, Merryman WD, Guan J, Momoi N, Stolz DB, et al. An elastic, biodegradable cardiac patch induces contractile smooth muscle and improves cardiac remodeling and function in subacute myocardial infarction. J Am Coll Cardiol 2007:49:2292-300.

[15] Serpooshan V, Zhao M, Metzler SA, Wei K, Shah PB, Wang A, et al. The effect of bioengineered acellular collagen patch on cardiac remodeling and ventricular function post myocardial infarction. Biomaterials 2013;34:9048-55.

[16] Guex AG, Kocher FM, Fortunato G, Körner E, Hegemann D, Carrel TP, et al. Finetuning of substrate architecture and surface chemistry promotes muscle tissue development. Acta Biomater 2012;8:1481-9.

[17] Dahlin RL, Kasper FK, Mikos AG. Polymeric nanofibers in tissue engineering. Tissue Eng Part B-Rev 2011;17:349-64.

[18] Mondal D, Tiwari A. Electrospun Nanomatrix for Tissue Regeneration. Biomedical Materials and Diagnostic Devices. New York: John Wiley \& Sons; 2012. p. 561-80.

[19] Del Gaudio C, Bianco A, Grigioni M. Electrospun bioresorbable trileaflet heart valve prosthesis for tissue engineering: in vitro functional assessment of a pulmonary cardiac valve design. Ann Ist Super Sanita 2008:44:178-86.

[20] Guan J, Wang F, Li Z, Chen J, Guo X, Liao J, et al. The stimulation of the cardiac differentiation of mesenchymal stem cells in tissue constructs that mimic myocardium structure and biomechanics. Biomaterials 2011;32:5568-80.

[21] Kenar H, Kose GT, Toner M, Kaplan DL, Hasirci V. A 3D aligned microfibrous myocardial tissue construct cultured under transient perfusion. Biomaterials 2011;32:5320-9.

[22] Sreerekha PR, Menon D, Nair SV, Chennazhi KP. Fabrication of electrospun poly (lactide-co-glycolide)-fibrin multiscale scaffold for myocardial regeneration in vitro. Tissue Eng Part A 2012;13:13.

[23] Kai D, Prabhakaran MP, Jin G, Ramakrishna S. Guided orientation of cardiomyocytes on electrospun aligned nanofibers for cardiac tissue engineering. J Biomed Mater Res Part B-Appl Biomater 2011;98B:379-86.

[24] Parrag IC, Zandstra PW, Woodhouse KA. Fiber alignment and coculture with fibroblasts improves the differentiated phenotype of murine embryonic stem cell-derived cardiomyocytes for cardiac tissue engineering. Biotechnol Bioeng 2012;109:813-22.

[25] Zong X, Bien H, Chung C-Y, Yin L, Fang D, Hsiao BS, et al. Electrospun finetextured scaffolds for heart tissue constructs. Biomaterials 2005;26:5330-8.

[26] Woodruff MA, Hutmacher DW. The return of a forgotten polymerpolycaprolactone in the 21st century. Prog Polym Sci 2010;35:1217-56.

[27] Cipitria A, Skelton A, Dargaville TR, Dalton PD, Hutmacher DW. Design, fabrication and characterization of PCL electrospun scaffolds-a review. J Mater Chem 2011;21:9419-53.

[28] Ishii O, Shin M, Sueda T, Vacanti JP. In vitro tissue engineering of a cardiac graft using a degradable scaffold with an extracellular matrix-like topography. J Thorac Cardiovasc Surg 2005;130:1358-63.

[29] Shin M, Ishii O, Sueda T, Vacanti JP. Contractile cardiac grafts using a novel nanofibrous mesh. Biomaterials 2004;25:3717-23.

[30] Choi JS, Lee SJ, Christ GJ, Atala A, Yoo JJ. The influence of electrospun aligned poly(epsilon-caprolactone)/collagen nanofiber meshes on the formation of self-aligned skeletal muscle myotubes. Biomaterials 2008;29:2899-906.

[31] Chen ZCC, Ekaputra AK, Gauthaman K, Adaikan PG, Yu H, Hutmacher DW. In vitro and in vivo analysis of co-electrospun scaffolds made of medical grade poly(epsilon-caprolactone) and porcine collagen. J Biomater Sci-Polym Ed 2008;19:693-707.

[32] Callegari A, Bollini S, Iop L, Chiavegato A, Torregrossa G, Pozzobon M, et al. Neovascularization induced by porous collagen scaffold implanted on intact and cryoinjured rat hearts. Biomaterials 2007;28:5449-61.

[33] Hegemann D, Hossain MM, Balazs DJ. Nanostructured plasma coatings to obtain multifunctional textile surfaces. Prog Org Coat 2007;58:237-40.

[34] Hossain MM, Hegemann D, Fortunato G, Herrmann AS, Heuberger M. Plasma deposition of permanent superhydrophilic a-C: H: N films on textiles. Plasma Processes Polym 2007;4:471-81.

[35] Körner E, Fortunato G, Hegemann D. Influence of RF plasma reactor setup on carboxylated hydrocarbon coatings. Plasma Processes Polym 2009;6:119-25.

[36] Guex AG, Fortunato G, Hegemann D, Tevaearai HT, Giraud MN. General protocol for the culture of cells on plasma-coated electrospun scaffolds. Methods Mol Biol (Clifton, NJ) 2013;1058:119-31.

[37] Landa N, Miller L, Feinberg MS, Holbova R, Shachar M, Freeman I, et al. Effect of injectable alginate implant on cardiac remodeling and function after recent and old infarcts in rat. Circulation 2008;117:1388-96.

[38] Takagawa J, Zhang Y, Wong ML, Sievers RE, Kapasi NK, Wang Y, et al. Myocardial infarct size measurement in the mouse chronic infarction model: comparison of area- and length-based approaches. J Appl Physiol 2007;102:2104-11.

[39] Ulger H, Karabulut AK, Pratten MK. Labelling of rat endothelial cells with antibodies to vWF, RECA-1, PECAM-1, ICAM-1, OX-43 and ZO-1. Anat Histol Embryol 2002;31:31-5.

[40] Saliba Y, Mougenot N, Jacquet A, Atassi F, Hatem S, Fares N, et al. A new method of ultrasonic nonviral gene delivery to the adult myocardium. J Mol Cell Cardiol 2012;53:801-8.

[41] Hegemann D, Körner E, Guimond S. Reply to: "Testing the hypothesis: comments on plasma polymerization of acrylic acid revisited". Plasma Processes Polym 2010;7:371-5.

[42] Körner E, Rupper P, Lübben JF, Ritter A, Rühe J, Hegemann D. Surface topography, morphology and functionality of silver containing plasma polymer nanocomposites. Surf Coat Technol 2011;205:2978-84.

[43] Baraniak PR, McDevitt TC. Stem cell paracrine actions and tissue regeneration. Regen Med 2010;5:121-43. 
[44] Guex AG, Romano F, Marcu IC, Tevaearai HT, Ullrich ND, Giraud MN. Culture of cardiogenic stem cells on PCL-scaffolds: Towards the creation of beating tissue constructs. IASTED Conference Proceedings 791, Biomedical Engineering 2013.

[45] Franz S, Rammelt S, Scharnweber D, Simon JC. Immune responses to implants A review of the implications for the design of immunomodulatory biomaterials. Biomaterials 2011;32:6692-709.

[46] Cao H, McHugh K, Chew SY, Anderson JM. The topographical effect of electrospun nanofibrous scaffolds on the in vivo and in vitro foreign body reaction. J Biomed Mater Res, Part A 2010;93A:1151-9.

[47] Rane AA, Chuang JS, Shah A, Hu DP, Dalton ND, Gu Y, et al. Increased infarct wall thickness by a bio-inert material is insufficient to prevent negative left ventricular remodeling after myocardial infarction. PLoS One 2011:6.
[48] Enomoto Y, Gorman JH, Moainie SL, Jackson BM, Parish LM, Plappert T, et al Early ventricular restraint after myocardial infarction: extent of the wrap determines the outcome of remodeling. Ann Thorac Surg 2005;79:881-7.

[49] Chen QZ, Harding SE, Ali NN, Lyon AR, Boccaccini AR. Biomaterials in cardiac tissue engineering: ten years of research survey. Mater Sci Eng R-Rep 2008;59:1-37.

[50] Sabbah HN, Sharov VG, Gupta RC, Mishra S, Rastogi S, Undrovinas AI, et al. Reversa of chronic molecular and cellular abnormalities due to heart failure by passive mechanical ventricular containment. Circ Res 2003;93:1095-101.

[51] Giraud MN, Ayuni E, Cook S, Siepe M, Carrel TP, Tevaearai HT. Hydrogel-based engineered skeletal muscle grafts normalize heart function early after myocardial infarction. Artif Organs 2008;32:692-700. 